J. Lake Sci.(湖泊科学), 2018, 30(3): 597-610

DOI 10. 18307/2018. 0302

(c) 2018 by Journal of Lake Sciences

\title{
湖泊生态系统产甲烷与甲烷氧化微生物研究进展”
}

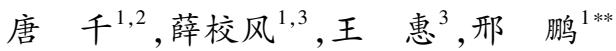 \\ (1:中国科学院南京地理与湖泊研究所湖泊与环境国家重点实验室,南京 210008) \\ (2: 中国科学院大学, 北京 100049) \\ (3: 南京师范大学生命科学学院, 南京 210046)
}

\begin{abstract}
摘 要: 湖泊生态系统是重要的大气甲烷来源, 其甲烷释放量占全球自然生态系统的 $40 \%$. 产甲烷和甲烷氧化微生物在 湖泊甲烷生产和消耗过程中发挥关键作用. 本文综述了近期有关湖泊生态系统甲烷产生与氧化过程的研究进展, 重点介 绍产甲烷与甲烷氧化微生物在湖泊中的分布特征、代谢途径以及调控机制. 现有研究表明, 湖泊中甲烷的生成不仅仅依 靠赋存于沉积物和水体厌氧层的产甲烷古菌, 还可能来自有氧环境中其他产甲烷微生物的代谢作用. 湖泊中的甲烷在脱 离水体逸散至大气之前, 被甲烷氧化微生物利用, 转化成二氧化碳和小分子有机化合物 (如甲醇、甲醛和甲酸等). 除了传 统依赖氧气作为电子受体的好氧氧化过程外, 新近研究还揭示了多种厌氧甲烷氧化过程, 包括依赖还原硫酸盐、硝酸盐 和亚硝酸盐以及 $\mathrm{Fe}^{3+} / \mathrm{Mn}^{4+}$ 等金属离子的甲烷氧化过程. 文献综合分析表明, 反硝化型厌氧甲烷氧化过程主要发生在淡 水湖泊中, 而硫酸盐还原型主要发生在高盐度或者高碱度湖泊中. 水体温度、溶解氧浓度可以显著影响产甲烷与甲烷氧 化微生物的丰度与群落结构, 其他湖泊环境条件, 如盐度、 $\mathrm{pH}$ 和有机质类型等都可能改变产甲烷与甲烷氧化微生物的分 布和代谢活性. 不同湖泊类型的比较研究, 有助于全面掌握影响湖泊产甲烷与甲烷氧化微生物的时空分布与代谢特征的 主导因素.
\end{abstract}

关键词: 湖泊生态系统; 产甲烷菌; 甲烷氧化菌; 厌氧甲烷氧化菌; 影响因子

\section{New knowledge of methanogens and methanotrophs in lake ecosystems}

\author{
TANG Qian ${ }^{1,2}$, XUE Xiaofeng ${ }^{1,3}$, WANG Hui ${ }^{3} \&$ XING Peng ${ }^{1 * *}$ \\ (1: State Key Laboratory of Lake and Environment, Nanjing Institute of Geography and Limnology, Chinese Academy of Sci- \\ ences, Nanjing 210008, P.R.China) \\ (2: University of Chinese Academy of Sciences, Beijing 100049, P.R.China) \\ (3: College of Life Sciences, Nanjing Normal University, Nanjing 210046, P.R. China)
}

Abstract: Inland waters, especially lakes are important methane sources to the atmosphere, which contributed to $40 \%$ of the total methane production from the global natural ecosystems. The methanogens and methanotrophs play key roles in the reactions of methane productions and consumptions in lake ecosystems. New discoveries of methane generation and oxidation progress in lake environments have been reviewed in this manuscript, in which the emphasis was put on the distribution, metabolism and regulation of methanogens and methanotrophs in natural lakes. The current researchers found that the methane in lakes is produced not only by the methanogens lived in the sediment and anaerobic water layer, but also by the microbes survived in the aerobic water. Current knowledge was consensus that most of the methane was oxidized by the methane oxidation process and transformed into carbon dioxide, methanol, formaldehyde or formic acid before it escaping from the water. Besides the traditional methane oxidation based on oxygen reduction, anaerobic oxidation of methane ( $\mathrm{AOM}$ ) was the important supplementary process in natural lakes. Researches indicated there were at least three major AOM processes in lakes, which were sulfate-dependent AOM, nitrite- and nitrate-dependent $\mathrm{AOM}$ as well as $\mathrm{Fe}^{3+} / \mathrm{Mn}^{4+}$-dependent AOM. Niches separations were identified among different AOM processes, for example,

* 国家自然科学基金项目 (31722008,91751111,31370508)、中国科学院青年创新促进会项目(2014273) 和湖泊与环 境国家重点实验室开放研究基金项目 (2012SKL005) 联合资助. 2017-10-16 收稿; 2017-11-19 收修改稿. 唐千 (1991 ) ,男,硕士研究生; E-mail: 18762102346@ 163.com.

** 通信作者; E-mail: pxing@ niglas.ac.cn. 
the sulfate-dependent AOM were generally detected in the soda and saline lakes, whereas the nitrite- and nitrate-dependent AOM took place in the freshwater lakes. Water temperature and dissolved oxygen were identified to be the most important factors that significantly influencing the abundance of methanogens and methanotrophs, as well as the community composition of these microbes. Actually, microorganisms participated in the methane production and oxidation could be affected by multiple factors in a certain ecosystem, such as $\mathrm{pH}$, organic matter and salinity. More types of lakes need to be studied in order to reveal the pattern of the spatial-temporal distribution of methanogens and methanotrophs and the mechanisms of metabolism regulation.

Keywords: Lake ecosystem; methanogens; methanotrophs; anaerobic oxidation of methane; impact factors

近 30 年来, 大气中甲烷含量已经增加了近 5 倍, 截止 2016 年, 大气中甲烷浓度已经达到 $1.32 \mathrm{mg} / \mathrm{m}^{3}$, 而 且全球生态系统还以每年 $540 \mathrm{Tg}$ 的速度继续向大气释放 ${ }^{[1-2]}$. 由于甲烷在百年尺度上的单分子增温效应是 二氧化碳的 $28 \sim 34$ 倍 ${ }^{[3-4]}$, 即使甲烷只占大气中所有温室气体的 5\% 10\%, 其对全球温室效应的贡献率也 达到了 $30 \% \sim 40 \%{ }^{[5]}$. 随着大气中甲烷含量的持续增加, 甲烷对全球温室效应的贡献比例也会越来越高. 大 气中的甲烷主要来自人类生产活动以及自然生态系统释放, 其中自然生态系统释放量占总释放量的 $40 \%$ $50 \%{ }^{[6-7]}$. 在自然释放源中, 湖泊生态系统释放量约占自然生态系统总释放量的 $16 \% \sim 24 \%{ }^{[8]}$, 而且随着湖泊 富营养化加剧, 以及温室效应导致的高纬度寒冷地区湖泊的冰盖融化, 湖泊甲烷释放量呈现逐年增加的趋 势 ${ }^{[5]}$. 由于湖泊在全球甲烷释放源中占有重要地位, 因此关注湖泊生态系统的甲烷产生和消耗过程就显得 尤为重要.

甲烷从湖泊释放到大气中, 是产甲烷过程与甲烷氧化过程的最终结果, 因此产甲烷与甲烷氧化微生物 在甲烷的转化过程中起着决定性作用 ${ }^{[2]}$. 产甲烷微生物可以利用湖泊中的小分子有机物, 在甲基辅酶 $\mathrm{M}$ 还 原酶作用下合成甲烷, 是湖泊中甲烷的主要来源. 尽管传统观点认为甲烷的产生是严格意义上的厌氧过程, 多发生在沉积物和分层水体的厌氧层, 这一过程中主要依靠产甲烷古菌的作用 ${ }^{[9]}$. 但是, 有研究发现湖泊有 氧水体中可以存在甲烷的超饱和现象, 进一步的研究也证实了富氧水体会产生大量的甲烷 ${ }^{[10]}$. 研究人员发 现印度尼西亚 Matano 湖有氧水体中的嗜甲基菌在分解甲基磷的过程中会释放大量的甲烷 ${ }^{[11]}$; 此外, 还有研 究发现有氧水体产甲烷菌可以通过一种特殊的不受氧影响的途径产生甲烷 ${ }^{[12]}$. 这些发现进一步拓宽了对 于湖泊中产甲烷途径的认识, 突破了厌氧的环境条件以及产甲烷古菌参与这两个传统意义上的必要条件.

湖泊生态系统中产生的甲烷在扩散进人大气之前, 有相当部分会被甲烷氧化微生物利用. Alaska 湖一 年中输人的碳有 $55 \%$ 被转化为甲烷, 但其中 $36 \%$ 的碳又经甲烷氧化被再次利用 ${ }^{[13-14]}$; Matano 湖产生的甲烷 有 $50 \%$, 极端情况时甚至会有 $90 \%$ 被氧化过程消耗 ${ }^{[6,11,15]}$. 因此甲烷氧化微生物在有效降低湖泊温室效应 方面发挥着重要作用. 甲烷氧化过程根据反应利用的电子受体大致可以分为好氧甲烷氧化和厌氧甲烷氧化 过程两种类型. 好氧甲烷氧化过程主要依靠好氧甲烷氧化细菌完成. 在湖泊生态系统中, 好氧甲烷氧化菌分 布较为广泛, 不同营养水平、不同纬度的湖泊中都发现大量的甲烷氧化菌 ${ }^{[16-18]}$. 厌氧甲烷氧化则是一个较为 复杂的过程, 主要依靠厌氧甲烷氧化古菌与其他阴离子还原细菌的耦合作用, 目前发现的类型主要有硫酸 盐还原型和硝酸盐 (和亚硝酸盐) 还原型. 由于湖泊中硫酸盐浓度普遍较低, 因此大部分湖泊生态系统以耦 合硝酸盐还原的厌氧甲烷氧化为主, 但在一些极端盐湖中硫酸盐还原细菌的丰度要远高于硝酸盐类还原细 菌 ${ }^{[19-20]}$. 更有研究发现, 湖泊中的厌氧甲烷氧化过程也可以不依赖厌氧甲烷氧化古菌参与, 归属于细菌 NC10 门的微生物可以独自完成反硝化和甲烷氧化过程 ${ }^{[21]}$.

湖泊甲烷产生与氧化微生物的重要性不言而喻, 且近期有关湖泊甲烷代谢过程的研究取得了一些突破 性的进展, 但尚无最新研究进展的综述. 本文对近几年有关全球湖泊产甲烷与甲烷氧化微生物的研究进行 了梳理, 综述了全球湖泊甲烷释放量规模, 不同类型湖泊产甲烷与甲烷氧化微生物的分布特征、代谢途径以 及调控机制, 总结了湖泊中影响产甲烷与甲烷氧化微生物的主要因素, 并对未来的研究趋势做了展望.

\section{1 湖泊甲烷产生与氧化过程}

\section{1 湖泊产甲烷过程新进展}

湖泊水体释放甲烷的过程是湖泊产甲烷与甲烷氧化过程综合作用的结果 (图 1). 通常, 沉积物以及深 水湖泊氧跃层以下的水体属于厌氧或者微有氧环境. 传统意义上认为这些厌氧环境是湖泊甲烷产生的主要 
场所, 其中的产甲烷过程由严格厌氧的产甲烷古菌起主导作用. 根据产甲烷古菌代谢路径, 产甲烷菌类型一 般分为甲基营养型、乙酸营养型和氢 $\left(\mathrm{H}_{2} / \mathrm{CO}_{2}\right)$ 营养型. 产甲烷古菌的分类标准及其代谢的过程与机制在国 内相关综述中已充分介绍,这里不再详细展开 ${ }^{[22-23]}$.

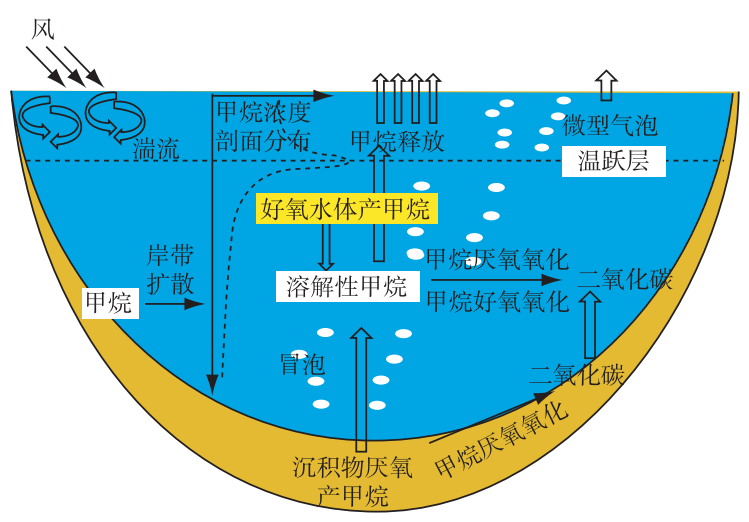

图 1 湖泊甲烷产生与氧化过程

Fig. 1 Progresses of methanogenesis and methanotrophs in lake

由于淡水湖泊中甲基化合物含量低, 乙酸型和氢营养型是湖泊生态系统主要的产甲烷反应类型 ${ }^{[24]}$. 但 在某些极地湖泊或者高海拔地区的盐湖中,如针对北极 Soda 湖以及青藏高原的班戈错, 甲基营养型被发现 是重要的产甲烷方式 ${ }^{[25-26]}$. 细致的研究发现 ${ }^{[22-23,25-26]}$, 湖泊产甲烷的途径和效率往往会沿着沉积物深度而产 生变化. 高海拔地区寡营养型湖泊沉积物中, 甲烷产生潜势随着沉积物深度的增加而显著增强, 而且表层沉 积物的产甲烷类型主要是氢营养型和乙酸营养型混合型, 但是随着深度增加, 氢营养型逐渐占据主导地位. 青藏高原班戈湖的研究发现, 在沉积物 $40 \sim 50 \mathrm{~cm}$ 深度以下, 产甲烷全部是通过氢营养型的代谢途径 ${ }^{[26]}$. Borrel 等对富营养化湖泊的研究发现, 表层沉积物的产甲烷量显著高于底层沉积物. 他认为有效有机质含量 随沉积物深度增加而降低可以较好地解释这一现象 ${ }^{[27]}$. 这表明, 有机质类型与含量会影响沉积物中产甲烷 微生物代谢类型与数量.

近期, 越来越多的研究揭示富氧湖泊的表层水体存在甲烷的超饱和现象 ${ }^{[12,28]}$. 在没有沉积物参与的情 况下, 水体仍然可以检测到大量溶解性甲烷, 这一现象指示有氧水体也可能存在甲烷产生途径 ${ }^{[10]}$. 原位围 隔实验中, 添加甲基磷的实验组甲烷释放量更加明显, 而只添加甲基物与磷的实验组产甲烷没有变化, 甚至 有被抑制的现象 ${ }^{[11]}$. 目前关于有氧水体产甲烷过程机制还有待进一步深人探索, 但有一些观点或者猜想得 到越来越多人的认同, 如有氧水体产甲烷过程很可能受到参与 C-P、C-S 裂解过程的微生物驱动, 而反应涉 及的相关酶类在非产甲烷微生物中普遍存在 ${ }^{[12]}$.

\section{2 甲烷氧化过程新进展}

由甲烷氧化菌驱动的甲烷消耗过程是湖泊生态系统碳循环的重要环节 ${ }^{[17]}$. 有研究表明, 湖泊甲烷氧化 对减少湖泊温室效应的贡献可以达到 $30 \%{ }^{[29]}$. 按照是否利用氧气作为电子受体, 可以将甲烷氧化过程分为 好氧甲烷氧化和戻氧甲烷氧化过程, 甲烷是这两种反应过程唯一的碳源. 好氧甲烷氧化过程主要通过好氧 甲烷氧化细菌的代谢活动来实现. 好氧甲烷氧化主要发生在湖泊有氧水体中, 湖泊沉积物产生的甲烷在进 人上覆水体后, 很大一部分在好氧甲烷氧化细菌的作用下被氧化成二氧化碳和水, 浅水湖泊中该过程消耗 的甲烷最多能占甲烷氧化量的 $80 \%$, 剩余部分则会通过扩散或者冒泡方式直接进人大气 ${ }^{[30-31]}$. 深水湖泊中, 温跃层及氧跃层的存在都会影响甲烷氧化过程 ${ }^{[2]}$, 湖泊沉积物及其底层缺氧水体产生的甲烷, 在向上扩散 过程中要经过相对稳定的氧跃层, 这些甲烷往往在进人表层富氧水体之前已经有相当部分被氧化, 这一过 程主要由厌氧甲烷氧化微生物主导 ${ }^{[32]}$.

与常见的好氧甲烷氧化过程不同, 关于湖泊厌氧甲烷氧化过程的研究从本世纪初才真正起步, 直到 2006 年才首次在湖泊沉积物中发现耦合硝酸盐或者亚硝酸盐的甲烷氧化反应 ${ }^{[7]}$. 厌氧甲烷氧化过程缺少氧 
作为电子受体, 需要利用替代电子受体, 如 $\mathrm{NO}_{3}^{-} 、 \mathrm{NO}_{2}^{-}$以及 $\mathrm{SO}_{4}^{2-}$ 等完成. 目前最为常见的与厌氧甲烷氧化古 菌合作, 实现氧化甲烷过程的细菌类型有硫酸盐还原菌、硝酸盐还原菌以及铁锰还原型细菌 ${ }^{[33}$. 研究发现, 耦合硫酸盐还原的厌氧甲烷氧化是一种逆产甲烷生产的反应过程, 古菌细胞内含有几乎所有能编码产甲烷 过程所需要酶的基因. 古菌与硫酸盐还原细菌形成互营复合体, 甲烷被氧化利用过程中可以为硫酸盐还原 反应提供所需电子 ${ }^{[34]}$. 由于厌氧甲烷氧化古菌生长缓慢, 只有极少部分菌株能够培养分离. 2015 年研究人 员采用苂光探针与苂光示踪技术, 发现了未经培养的硫酸盐还原细菌可以独立完成甲烷氧化与硫酸盐还 原, 这为甲烷氧化的研究又打开了新的视角 ${ }^{[20,35]}$. 潜在未知反应过程的不断揭示使得厌氧甲烷氧化成为湖 泊碳循环研究的热门领域 ${ }^{[36-37]}$.

在湖泊生态系统中, 耦合硫酸盐还原的厌氧甲烷氧化大多发生在硫酸盐含量较高的盐湖或者碱湖沉积 物中. 但是对于分布广泛的淡水湖泊, 因其硫酸盐含量要低得多, 甲烷氧化过程大多以耦合硝酸盐还原为主. 根据反应热力学原理, 与反硝化耦合的厌氧甲烷氧化过程比与硫酸盐还原耦合的过程更具有热力学优 势 ${ }^{[38]}$. 对亚热带半对流深水湖泊的研究发现, 氧是影响甲烷氧化途径的关键因素. 深水湖泊氧跃层的边界, 即有氧一无氧的分界线是戻氧甲烷氧化过程的阻断线, 在边界以上, 厌氧甲烷氧化过程立即消失, 在边界以 下, 甲烷氧化潜势达到最大值, 这一结果反映有氧一无氧边界恰是厌氧甲烷氧化反应的最佳环境 ${ }^{[39]}$. 在硝酸 盐含量较高的湖泊沉积物中, 厌氧甲烷氧化古菌丰度低, 但反硝化甲烷氧化菌的丰度高, 而且甲烷氧化反应 还在持续进行中, 这些现象指示可能存在不需要厌氧甲烷氧化古菌而能独立完成甲烷氧化与反硝化的微生 物. 经过单细胞基因测序, 研究人员确定这类细菌归属于 NC10 门 ${ }^{[40]}$. 研究人员通过环境转录组学方法, 确 认反硝化甲烷氧化细菌拥有一套完整的好氧甲烷氧化途径, 并且拥有除 $\mathrm{N}_{2} \mathrm{O}$ 还原酶以外完整的反硝化基 因簇 ${ }^{[41]}$.

\section{2 湖泊生态系统中产甲烷与甲烷氧化微生物}

\section{1 湖泊中的产甲烷微生物}

产甲烷微生物在湖泊生态系统中的分布极其广泛, 从热带湖泊到极地冰层覆盖的湖泊, 从淡水湖到高 浓度盐湖都有其身影 ${ }^{[42]}$. 广泛意义上, 产甲烷微生物是一个复杂庞大功能群, 从有机质分解到最终产生甲 烷这一过程所涉及的所有微生物都可以称作产甲烷微生物. 但一般来说, 产甲烷微生物特指能够利用有机 质降解产生的乙酸、 $\mathrm{H}_{2} / \mathrm{CO}_{2}$ 以及甲基化合物产生甲烷的一类古菌, 是有机质厌氧分解食物链的末端成员. 研 究表明, 产甲烷古菌是一种严格厌氧的微生物, 对氧极为敏感. 深水湖泊氧跃层下边界是产甲烷古菌分布的 界限, 从边界往上产甲烷古菌丰度呈现断崖式下降 ${ }^{[43]}$. 传统意义上认为湖泊生态系统中的甲烷也主要来自 缺氧沉积物. 但是随着有氧水体甲烷超饱和现象的揭示, 使得有氧水体产甲烷过程得到越来越多的关 注 ${ }^{[4-45]}$. 尽管目前这一反应的生物化学机制还不完善, 但产甲烷古菌不再是湖泊生态系统中唯一的产甲烷 微生物, 对有氧水体中能够产生甲烷的其他微生物的研究将成为热点.

2.1.1 厌氧环境中的产甲烷古菌 湖泊生态系统产甲烷微生物的研究几乎与产甲烷菌的研究是同步的, 18 世纪就已经有意大利学者发现湖泊产甲烷现象. 1950s, 随着 Hungate 厌氧分离技术的发展, 首次获得湖泊沉 积物中产甲烷菌的纯培养菌株, 这算是第一次真正意义上在湖泊生态系统中发现产甲烷菌. 1976 年古菌被 作为单独一个域 (domian) 提出, 产甲烷古菌也因此获得命名. 起初产甲烷古菌主要包括 5 个大目: 甲烷杆菌 目 (Methanobacteriales)、甲烷球菌目 (Methanococcales)、甲烷八叠球菌目 (Methanosarcinales)、甲烷微菌目 (Methanomicrobiales) 和甲烷火菌目 (Methanopyrales). 湖泊生态系统中发现的产甲烷菌主要有甲烷杆菌目、 甲烷球菌目和甲烷微菌目. 尽管在其他环境中甲烷八叠球菌目已经被成功分离, 但在湖泊系统中只是在沉 积物中发现其踪迹 ${ }^{[46]}$. 此后直至 1990s 末期, 随着 16S rRNA 基因测序技术的迅速发展, 产甲烷菌家族才陆 续迎来新成员. 研究人员在水稻土中发现了新的产甲烷菌株, 命名为甲烷胞菌目 (Methanocelles) ${ }^{[47]}$; 还有一 类在反刍动物胃中以及白蚁肠道中发现的新产甲烷菌, 后被称为甲烷原体目 (Methanoplasmatales) ${ }^{[48]}$. 尽管 在湖泊生态系统中还未分离获得相关的微生物菌株, 但通过分子探针方法, 已经检测到了湖泊系统存在这 些微生物的相关基因 ${ }^{[42]}$.

随着研究的深人, 2000 年前后成为湖泊产甲烷古菌研究的黄金时期, 大量科、属分类水平上的产甲烷古 
菌被确定. 由于湖泊生态系统更适合于氢营养型和乙酸营养型产甲烷菌生存, 因此湖泊沉积物中产甲烷菌 的主导类群是利用乙酸的甲烷毛菌科 (Methanosaetaceae) 以及利用 $\mathrm{H}_{2} / \mathrm{CO}_{2}$ 的甲烷微菌科 (Methanomicrobiaceae) 和甲烷杆菌科 (Methanobacteriaceae). 能够同时利用两种底物的甲烷球菌科( Methanosarcinaceae) 和能 够利用甲醇、甲胺和 $\mathrm{CO}_{2} / \mathrm{H}_{2}$ 的甲烷八叠球菌属 (Methanosarcina) 也在很多湖泊沉积物中被发现 ${ }^{[49-50]}$. 运用分 子检测手段, 在半对流的 Michigan 湖中发现大量甲烷八叠球菌属的微生物 ${ }^{[51-52]}$. 研究人员对各种类型湖泊 中的产甲烷古菌开展了大量的研究, 其中以富营养化浅水湖泊和寡营养深水湖泊的研究最多. Scholten 等发 现, 富营养化 Zegveld 湖中能够利用乙酸的甲烷丝菌属 (Methanosaeta) 是优势种 ${ }^{[51]}$; Whitby 等却发现 Priest Pot 湖中的产甲烷菌以甲烷囊菌属 (Methanoculleus) 为优势种 ${ }^{[52]}$. Yang 在研究中营养型湖泊 Amazonian 湖时 发现氢营养型是主要的产甲烷代谢类型, 其中甲烷八叠球菌目是分布最为广泛的甲烷菌种类 ${ }^{[53]}$. 对于葟营 养深水湖泊, 产甲烷活动主要来自于沉积物, 此外水体的戻氧层也检测到产甲烷古菌. 在对 Matano 湖的研究 中发现, 氢营养型的甲烷微菌目是主要的优势种, 约占全部产甲烷菌数量的 $80 \%$, 而甲烷八叠球菌目仅 有 $4 \%{ }^{[17]}$.

此外, 根据适合生存的温度, 产甲烷菌还可以分成嗜热菌、嗜温菌和嗜冷菌 ${ }^{[54]}$. 针对极地嗜冷菌和地热 嗜热菌的研究, 尤其是极地湖泊方面的研究成为近年来湖泊产甲烷古菌最为热门的研究方向之一. 研究人 员在南北两极和青藏高原湖泊中发现了大量嗜冷产甲烷菌. 南极地区湖泊的产甲烷菌包括甲烷球菌属 (Methanococcus)、产甲烷菌属 (Methanogenium)、甲烷八叠球菌属和甲烷叶菌属 (Methanolobus) 4 大类群 ${ }^{[55]}$. 针对北极地区湖泊研究更加丰富, 在北极高纬度康沃利斯岛的 Char 和 Small 湖以亨氏螺旋菌属 (Methanoregula) 为主 ${ }^{[56]}$, 瑞士 Zug 淡水湖分离出 Methanococcoides alaskense, Miskin 等在英国 Windmere 湖分离出了 Methanospirillum hungatei 和甲烷八叠球菌属 (Methanosarcina $)^{[57]}$. 此外, 从低温湖泊中分离的产甲烷菌还有 以甲基类化合物为主要产甲烷底物的 Methanobacterium subterraneum 和 Methanomethylovorans hollandica ${ }^{[58-59]}$. 除淡水湖泊外, 盐湖中分离的产甲烷菌大多属于甲基营养型, 这与海水中的分布相一致, 主要属于甲烷碱菌 属 (Methanosalsum $)^{[60]}$. 盐湖与淡水湖产甲烷古菌的群落组成有着明显差异, 反映了盐度、碱度等环境因素 能显著影响产甲烷古菌的生态分布.

2.1.2 有氧水体中的产甲烷微生物 有研究发现, 仅占全球 $0.9 \%$ 面积的湖泊却向大气释放了与占全球 $70 \%$ 面积的海洋释放的大致等量的甲烷 ${ }^{[12,27]}$, 这也让人产生疑问: 湖泊所释放的甲烷全都来自沉积物和底层水 体吗? 表层有氧水体是否能够产生甲烷呢? 产甲烷过程一直被认为是严格厌氧过程, 对氧的敏感性很高, 因此关于湖泊产甲烷菌的研究也主要关注沉积物和缺氧水体. 实际上, 陆地生态系统中真核生物在有氧条 件下产甲烷的现象已经被报道 ${ }^{[61]}$. 在沙漠土壤中, 产甲烷古菌在有氧条件下产生甲烷的现象也已经被发 现 ${ }^{[62]}$. 同样是水环境的海洋中, 有氧水体中微生物利用来自浮游植物的甲基化合物产生甲烷的现象, 已经 一步步地预示湖泊水体有氧层存在产甲烷过程的可能性 ${ }^{[63]}$.

湖泊水体产甲烷过程研究最大的困难在于难以区分甲烷产生的具体位置, 例如, 到底来自底层水体还 是表层有氧水体? 围隔实验系统的出现则很好地解决了这一困惑. 这是一个人为可调控将水体与沉积物分 离的中尺度生态系统, 溶解氧检测显示系统底部不处于厌氧状态 ${ }^{[10]}$. 通过围隔实验系统, 科研人员在德国 Stechlin 湖和加拿大 Cromwell 湖都发现了表层水体甲烷的超饱和富集现象 ${ }^{[10,44]}$. Stechlin 湖表层水体中检测 到产甲烷菌, 其中游离态产甲烷菌主要为甲烷微菌目, 大量分布在水深 $6 \mathrm{~m}$ 处; 附着态产甲烷菌主要生活在 水深 6 和 $9 \mathrm{~m}$ 处, 以甲烷丝菌属和亨氏螺菌属为主. 虽然没有直接的证据表明甲烷来自这些产甲烷菌, 但通 过宏转录组测序发现了产甲烷功能基因的转录行为 ${ }^{[44]}$. 但是在 Matano 湖 $^{[11]}$, 表层水体的宏基因组测序结 果中, 只分析到少量产甲烷古菌, 却发现了大量嗜盐细菌属 (Halobacteria). 将宏基因组与转录组数据相匹 配时研究人员未找到产甲烷古菌的表达, 表明尽管其存在于水体中, 但其对产甲烷过程并没有贡献. 能够利 用有机磷的微生物, 如 Methylobacterium podarium、Agrobacterium tumefaciens、根瘤菌 (Rhizobium spp.) 和 Pantoea ananatis 却在培养试验中产生了甲烷. 研究人员发现 $p h n J$ 基因在表层水体中磷酸盐含量较低时, 表 达量是最高的 ( $p h n J$ 是能够编码 C-P 裂解酶的基因, 是利用甲基磷的微生物并释放甲烷的标记基因), 而且 只有添加甲基磷的培养组中会明显产生甲烷, 并检测到 phnJ 基因表达. 上述结果表明, Matano 湖水体有氧 层产生的甲烷很可能是微生物在利用甲基磷时的副产物 ${ }^{[11]}$. 在美国 Yellowstone 湖的研究也发现了这一现 
象, 但其检测到的微生物主要是假单胞菌属 (Pseudomonas $)^{[45]}$. 也有研究发现, 甲烷释放量的增加往往伴随 着蓝藻暴发, 这可能是放线菌与拥有 C-P 裂解酶的蓝藻共同作用的结果 ${ }^{[12]}$. 不仅如此, 在北极地区, Damn 等研究发现产甲烷微生物能够利用二甲基硫酸盐获取能量, 同时释放甲烷. 利用该化合物的最后一步反应 是厌氧条件下的甲基还原过程, 但是测序结果未发现合成甲基还原酶的基因, 由此 Damn 等推测产甲烷微生 物可能是通过呼吸来让细胞质保持一种厌氧状态, 从而实现甲基还原并产生甲烷的 ${ }^{[64]}$.

事实上, 直到 2011 年关于湖泊有氧水体甲烷产生的过程和机制研究才逐渐被人们关注, 相继有多篇论 文发表在《美国科学院院刊》 $\rangle^{[4]}$ 、《自然通讯》 ${ }^{[10]}$ 、《海洋与湖沼 $\rangle^{[28]}$ 等重要刊物. 针对有氧水体产甲烷过程 的机制解析存在两派观点: 一派认为, 有氧水体中微生物仍然采用传统的代谢途径合成甲烷, 只是微生物存 在某种机制能够抵消氧的影响, 比如通过呼吸作用实现细胞内部的厌氧状态; 另一派认为, 存在全新的产甲 烷方式, 例如非产甲烷古菌在代谢含甲基化合物的过程中, 其含有的能裂解 C-P 或者 C-S 键并释放甲烷的 酶体系对氧不敏感, 可以有氧产生甲烷 ${ }^{[12]}$. 目前发现的产甲烷微生物只占全部微生物的 $1 \%$, 尚有大量产甲 烷微生物未获得分离培养, 因此自然界存在好氧产甲烷的微生物并非不可能.

\section{2 湖泊中的甲烷氧化微生物}

甲烷氧化过程是自然界调控甲烷含量的最重要环节, 研究显示, 湖泊产生的甲烷最高有 $90 \%$ 会被甲烷 氧化菌利用, 极大地降低了湖泊生态系统的温室效应贡献率. 甲烷氧化菌可以分为好氧甲烷氧化菌和厌氧 甲烷氧化菌. 表 1 是在其他综述基础上, 结合最近几年甲烷氧化菌的最新研究 ${ }^{[33,42]}$, 列举的甲烷氧化菌分类 情况 ${ }^{[64]}$. 好氧甲烷氧化菌易于培养, 研究获得的种类也更为丰富; 厌氧甲烷氧化菌的研究, 一直到 2006 年随 着还原硝酸盐和亚硝酸盐氧化甲烷过程的发现才逐渐开展起来.

2.2.1 湖泊中的好氧甲烷氧化微生物好氧甲烷氧化微生物利用自身携带的甲烷单加氧酶 (methane monooxygenase, MMO) 首先催化甲烷氧化为甲醇, 通过甲醇脱氢酶催化, 甲醇被氧化生成甲酫. 甲醛通过丝氨酸途 径 (Serine pathway) 或单磷酸核酮糖途径 (RuMP pathway) 被转化为细胞质, 或者甲醛被氧化成甲酸, 最终转 化为二氧化碳. 编码颗粒态甲烷单加氧酶 ( $\mathrm{pMMO}$ ) 亚基的 $p m o A$ 基因, 几乎存在于所有甲烷氧化菌中, 因此 $p m o A$ 基因已经成为甲烷氧化菌生态学研究中广为采用的生物标记物.

好氧甲烷氧化菌在湖泊中的分布极为广泛, 极地湖泊也有好氧甲烷氧化菌的报道. 好氧甲烷氧化菌早 在 1906 年就被首次发现, 1990s 分子生物学技术的进步推动了相关研究的迅速发展. Andriam 首先运用 $16 \mathrm{~S}$ rRNA 和 $P m o A$ 基因作为分子标记研究自然条件下湖泊沉积物中的好氧甲烷氧化菌的分布, 结果显示沉积物 中的甲烷氧化菌以甲基单胞菌属 (Methylomonas)、甲基弯曲菌属 (Methylosinus) 和甲基胞囊菌属 (Methylocystis) 为主 ${ }^{[34]}$. 进人 21 世纪, 甲烷氧化菌的研究进人了快车道, 并在湖泊生态系统取得了下列研究 进展: ( i ) 淡水湖泊生态系统中好氧甲烷氧化菌以 Type I 型甲烷氧菌中的甲基单胞菌属、甲基杆菌属 (Methylobacter)、甲基八叠球菌属 (Methylosarcina)、甲基球菌属 (Methylococcus) 和 Methylosoma 属为主 ${ }^{[65]}$. 在对 Washington 湖和 Constance 湖岸带沉积物的研究中发现, Type I 型占 pmoA 克隆文库序列的 $90 \%$, 比 Type II 型好氧甲烷氧化菌高 1 2 个数量级 ${ }^{[66-67]}$. 不过 Constance 湖水体分层研究发现不同深度甲烷氧化菌的组成 显著不同, 水深 $90 \mathrm{~m}$ 处主要是甲基杆菌属和甲基八叠球菌属; 但是在 $80 \mathrm{~m}$ 处, 只是甲基杆菌属占优势; 在 50 60 m 处 Type X 型的甲基球菌属和甲基暖菌属 (Methylocaldum) 则成为了优势种 ${ }^{[68]}$. Constance 湖沉积物 中 Type X 型甲烷氧化菌是主要优势种 ${ }^{[69]}$, Dumont 等利用 DNA-SIP 和 mRNA-SIP 相结合的方法, 发现在 Stechlin 湖中也以 Type I 型甲烷氧化菌为主要菌群 ${ }^{[70]}$. 对热带湖泊水体的研究发现 Type II 型在表层水体的 活性明显高于其他氧化菌, 但是 Type I 型在营养丰富的底层区域则更加丰富 ${ }^{[39,43]}$. 云南高原的淡水湖中好 氧甲烷氧化菌的数量显著高于其他寡营养型湖泊, 不过 Type I 型甲烷氧化菌仍然占很大比例 ${ }^{[71]}$. (ii) 在盐 湖中, 好氧甲烷氧化菌的种类基本以 Type I 型为主, 除了种属组成上存在差异. Mono 盐湖中, 甲基杆菌属 (Methylobacter)、甲基微菌属(Methylomicrobium)、甲基热菌属(Methylothermus) 和甲基胞囊菌属都有发现; 而 在俄罗斯 Lonar 盐湖中除了上述 4 个类群, 还有甲基单胞菌属、甲基暖菌属、甲基弯曲菌属和甲基帽菌属 (Methylocapsa $)^{[72]}$.

2.2.2 湖泊中的厌氧甲烷氧化微生物相对于好氧氧化过程, 厌氧甲烷氧化是比较新的途径. 1976 年在观测 海洋甲烷释放时, Hinrichs 首次发现庈氧甲烷氧化菌的存在 ${ }^{[42]}$. 同样还是在海洋中, 人们发现了厌氧甲烷氧 
化一般都伴随着 $\mathrm{SO}_{4}^{2-}$ 含量的降低, 由此推测厌氧甲烷氧化可以与硫酸盐还原过程耦合, $\mathrm{SO}_{4}^{2-}$ 代替氧气作为 反应电子受体 ${ }^{[34]}$. 2000 年通过显微细胞结合荧光示踪技术第一次直接观察到了厌氧甲烷氧化古菌 (ANME) $)^{[73]}$. 此后厌氧甲烷氧化与其他离子还原的过程逐渐被认识, 根据耦联的反应不同, AOM 目前主要 分为两种类型: 一种是硫酸盐还原型厌氧甲烷氧化 (Sulphate-dependent anaerobic methane oxidation, SAMO), 即甲烷氧化耦联硫酸盐还原; 另一种是反硝化型厌氧甲烷氧化 (Denitrification-dependent anaerobic methane oxidation, DAMO) , 即甲烷氧化耦联硝酸盐 (亚硝酸盐) 还原. 目前 ANME 有 3 个分支: ANME-1、 ANME-2、ANME-3 (表 1). 除了 ANME-2d 之外,其他分支都只参与 SAMO 反应.

表 1 甲烷氧化菌的分类

Tab.1 Category of methanotrophs

\begin{tabular}{|c|c|c|c|}
\hline 甲烷氧化菌 & 类型 & 门(纲) & 属(种) \\
\hline \multirow[t]{3}{*}{ 好氧甲烷氧化菌 } & $\mathrm{I}$ 型、X( Ib) 型 & $\gamma$ 变形菌 & $\begin{array}{l}\text { Methylomomas } 、 \text { Methylobacter } 、 \text { Methylosarcina } \\
\text { Methylomicrobium } 、 \text { Methylohalobius } \\
\text { Methylosphaera } 、 \text { Methylosoma } 、 \text { Methylothermus } \\
\text { Methylocaldum } 、 \text { Methylococcus }\end{array}$ \\
\hline & II 型 & $\alpha$ 变形菌 & $\begin{array}{l}\text { Methylosinus } 、 \text { Methylocystis } 、 \text { Methylocella } \\
\text { Methylocapsa } 、 \text { Methyloferula }\end{array}$ \\
\hline & 其他 & 疮微菌门 & $\begin{array}{l}\text { Methylokorus infernorum 、Acidimethylosilex } \\
\text { fumarolicum } 、 \text { Methyloacida kamchatkeensis }\end{array}$ \\
\hline \multirow[t]{2}{*}{ 厌氧甲烷氧化菌 } & 古菌 & 厌氧甲烷氧化古菌 & $\begin{array}{l}\text { ANME- } 1 \text { 、ANME-2a、ANME- } 2 b 、 \text { ANME- } 2 c \text { 、 } \\
\text { ANME- } 3 、 \text { ANME- } 2 d\end{array}$ \\
\hline & 细菌 & $\begin{array}{c}\mathrm{NC10} \text { 门 } \\
\text { 非 NC10 门 }\end{array}$ & $\begin{array}{l}\text { Candidatus Methylomirabilis oxyfera } \\
\text { Methylomirabilis oxyfera-like 微生物、非 NC10 门 }\end{array}$ \\
\hline
\end{tabular}

研究人员在研究湖泊厌氧甲烷氧化过程时, 发现了一种全新的厌氧甲烷氧化方式, 即甲烷氧化耦联硝 酸盐 (亚硝酸盐) 还原的 $\mathrm{DAMO}^{[64]}$. 湖泊中的硝酸盐含量明显高于海洋, 其甲烷产生效率是海洋的 1000 倍, 可能成为 DAMO 发生的理想场所 ${ }^{[12]}$. 湖泊中甲烷与硝酸盐、亚硝酸盐共存的现象很早就被发现,但一直到 2006 年, Raghoebarsing 等 ${ }^{[74]}$ 才在实验室条件下通过对污泥、湖泊沉积物等混合培养,获得了能够利用 $\mathrm{NO}_{2}^{-}$ 为电子受体的甲烷氧化微生物富集培养物, 证实了甲烷氧化可耦合亚硝酸盐的还原, 并将这一富集物命名 为 Candidatus M. oxyfera. 同位素标记结果显示古菌和细菌都参与了这一反应过程: 其中的细菌归属于非培 养的、只能通过环境基因序列定义的新菌门一 $\mathrm{NC10}$ 门细菌,其中的古菌在系统发育中的归类介于甲烷丝 状菌 (Methanosaeta) 和 ANME-2 之间, 后被确定为 ANME- $2 \mathrm{~d}^{[21]}$. 目前湖泊 DAMO 大多发生在深水湖泊深水 层沉积物中, 尚未在浅水湖泊或者沿岸带沉积物中发现 NC10 门细菌. 在 Constance 湖, 研究人员发现在深水 层和沉积物中, NC10 门细菌分布呈现明显不同, 与甲烷氧化量和亚硝酸盐消耗量有显著的一致性, 指示 DAMO 可能主要由 NC10 门细菌完成 ${ }^{[67,69,75-76]}$. 但在云南高原系列湖泊的研究中却发现, 尽管参与 DAMO 的 微生物与 Candidatus M. oxyfera 相似, 但是它们并不属于 NC10 门, 可能存在新的种类 ${ }^{[71]}$. Suz 湖中, 氧跃层 以下的甲烷氧化能力随着深度的增加而增强, 但是硫酸盐含量没有表现明显减少的现象, ANME 的数量也 没有显著的变化. 由于硝酸盐与亚硝酸盐的含量也可以忽略不计,因此看起来这一区域的 AOM 执行者“消 失了”. 后期研究人员通过控制实验添加 $\mathrm{Fe}^{3+}$ 离子与 $\mathrm{Mn}^{4+}$ 离子, 尽管在水深 $80 \mathrm{~m}$ 处发现明显的 $\mathrm{AOM}$ 增强的 现象, 但是未检测到金属阳离子被还原的现象 ${ }^{[77]}$. 上述研究表明, 在深水湖泊中可能存在与金属离子还原 有关的未知厌氧甲烷氧化途径, 由于目前对湖泊厌氧甲烷氧化过程认识有限, 甲烷在湖泊微生物之间的流 动与循环机制需要后续研究.

淡水湖泊生态系统中, 由于硫酸盐含量较低, SAMO 发生的几率较低; 而盐湖中, SAMO 仍然是 AOM 的 主要途径. 不过近期的湖泊研究中还发现了一些不同的现象, (i) 尽管研究人员检测到甲烷被氧化,但在基 因测序结果中却未找到古菌, 而硫酸盐还原细菌的表达丰度很高. 这一结果预示硫酸盐还原细菌很有可能 独立完成了甲烷氧化与硫酸盐还原反应 ${ }^{[20]}$. (ii) 在一些富铁、低硫的淡水深水湖中, 甲烷在从沉积物含铁硫 
层向上扩散的过程中, 含量逐渐下降, 同时检测到 $\mathrm{Fe}^{3+}$ 与 $\mathrm{SO}_{4}^{2-}$ 的还原, $\mathrm{ANME}-2 \mathrm{~d}$ 类群是主要的厌氧甲烷氧化 菌. 这说明 AOM 过程可能与高价铁离子或者硫酸盐还原耦合, 至少硫酸盐还原对 AOM 有一定贡献 ${ }^{[77]}$. 可 见, 淡水湖泊生态系统即使在 $\mathrm{SO}_{4}^{2-}$ 含量很低的情况下, 仍可能存在塊合硫酸盐与铁锰还原的厌氧甲烷氧化 反应, 而且 ANME- $2 \mathrm{~d}$ 可能不仅仅在氧化甲烷的过程中可以还原 $\mathrm{NO}_{3}^{-}$, 可能还有其他离子的还原过程.

\section{3 影响产甲烷菌与甲烷氧化微生物的主要因素}

\section{1 溶解氧}

环境中溶解氧含量或者氧化还原电位态势是甲烷产生与氧化过程最为关键的影响因素, 产甲烷与甲烷 氧化微生物的分布都与氧浓度密切相关. 氧对微生物的影响一般取决于微生物细胞内的酶对氧的耐受性, 如产甲烷古菌细胞内的若干辅酶因对氧气极为敏感, 因此在富氧条件下, 酶的活性会迅速下降, 甚至失 活 ${ }^{[27]}$. 一般来说, 甲烷主要由严格厌氧的产甲烷菌合成, 氧气浓度在 $0.7 \mathrm{mg} / \mathrm{L}$ 以上时, 产甲烷菌活性被完全 抑制, 因此, 湖泊沉积物和厌氧水体中的产甲烷过程通常是甲烷的最主要来源 ${ }^{[27,78-79]}$. 研究表明, 在有机质 较为丰富的 $0 \sim 60 \mathrm{~cm}$ 沉积物中, 随着深度增加, 溶解氧含量逐渐降低, 但甲烷产生量和产甲烷古菌丰度却逐 渐增加 ${ }^{[80]}$. 尽管有很多研究在表层水体中发现了大量产甲烷微生物, 但是这类微生物的产甲烷机制尚不清 楚, 目前猜测这类微生物在分解有机质产甲烷过程中涉及的酶对氧的敏感性较低, 或者这类微生物能够形 成细胞内无氧环境 ${ }^{[12]}$. 深层湖泊中氧跃层边界以下溶解性甲烷浓度往往达到最大, 在边界以上溶解性甲烷 浓度急剧下降. 研究发现, 这一过渡带通常也是甲烷氧化菌最活跃的地方, 沉积物和底层水体产生的甲烷在 这里被大量消耗. 在氧跃层边界以上, 微生物产甲烷能力迅速下降到几乎无法检测 ${ }^{[19]}$.

氧气浓度的变化对甲烷氧化的方式也有较大的影响. 如在对比利时温带富营养化湖泊 Dendrestone 湖 的研究中发现, 冬季水体溶解性甲烷浓度最高, 好氧甲烷氧化约占全部甲烷氧化量的 $80 \%$; 但在夏季, 水体 溶解氧浓度较低时, 厌氧甲烷氧化占主导地位, 而且以 DAMO 途径为主 ${ }^{[2]}$. 此外, 湖泊生态系统中的其他生 物也会对甲烷代谢过程产生重要影响. 有研究发现, 由于水生植物能够提供更多的溶解氧, 植物根系处甲烷 氧化菌的丰度、活性都有很大提高 ${ }^{[81]}$. 在亚热带浅水湖泊中, 夏季蓝藻暴发时, 不仅能够为产甲烷微生物提 供丰富的有机质,还能在表层水体形成局部厌氧环境, 促进甲烷的产生 ${ }^{[82]}$.

\section{2 温度}

温度是湖泊生态系统中重要的环境参数, 对产甲烷与甲烷氧化微生物的生命代谢和群落结构都会产生 重要影响. 在全球尺度上, 随着近 10 年全球增温, 湖泊生态系统向大气释放的甲烷总量已经升高 $10 \%{ }^{[83]}$. 在季节变化较为明显的温带湖泊, 夏季较高的温度会明显促进产甲烷菌的产甲烷量 ${ }^{[8,84]}$. Amy 等在研究五 大湖 (Laurentian Great Lakes) 时也发现, 温度上升会造成甲烷的大量释放 ${ }^{[4]}$. 北极和青藏高原地区湖泊近几 年甲烷释放量的迅速增加也与温度增加有密切的关联 ${ }^{[25]}$. 鄱阳湖的研究表明, 夏季湖泊甲烷释放量要明显 高于其他季节, 产甲烷菌的数量在夏季达到峰值, 但是在冬季甲烷氧化菌的丰度与活性反而达到最大 ${ }^{[31]}$. 温度对产甲烷与甲烷氧化微生物的群落结构也存在影响. 对全球 19 个不同地区淡水湖产甲烷古菌种群分 布研究发现, 热带地区的产甲烷类群与其他地区有明显差异, 其中约有 $80 \%$ 的种类是目前未知的类群, 未知 种类数量显著高于其他温度较低地区 ${ }^{[27]}$. 此外温度升高会增加两极地区冰川的消融速度, 不仅会改变当地 湖泊生态系统中的水文情况, 促进产甲烷活动发生, 同样会使冰封的产甲烷菌和甲烷氧化菌随水流进人周 边的湖泊中, 改变当地的甲烷微生物的群落结构 ${ }^{[85-87]}$.

在微观尺度上, 温度通过影响微生物新陈代谢速来调控微生物甲烷的产生与氧化过程. 美国研究人员 统计了全球 271 个湖泊近 20 年应对全球增温的反馈效应, 结果发现, 尽管低纬度/低海拔地区的湖泊温度只 在 $0.5^{\circ} \mathrm{C}$ 之内波动, 远低于高海拔高纬度地区的 $1^{\circ} \mathrm{C}$ 的范围, 但是低海拔/低纬度地区湖泊微生物的新陈代谢 变化速率要远高于高海拔和高纬度地区 ${ }^{[88]}$. 尽管极地地区生物代谢速率变化较小, 但其在应对极小范围温 度变化, 如 $0.1^{\circ} \mathrm{C}$ 时, 生物生命代谢速率变化更快 ${ }^{[89]}$. 温度的改变会影响微生物细胞内酶活性, 如温度增加 会促进细胞内产 $\mathrm{H}_{2}$ 酶活性, 进而促进产甲烷古菌, 尤其是乙酸型产甲烷古菌的生长. 在南极 Ace 湖, 嗜温产 甲烷菌的最佳生长温度为 $25 \sim 35^{\circ} \mathrm{C}$, 当温度降到 $0^{\circ} \mathrm{C}$ 以下时, 嗜温产甲烷菌迅速死亡, 从而被嗜冷产甲烷菌 所取代 ${ }^{[90]}$. 可见, 温度对湖泊产甲烷与甲烷氧化微生物的影响主要取决于微生物体内酶的耐受温度及其 
活性.

\section{3 其他因素}

除了溶解氧与温度外, 产甲烷与甲烷氧化微生物活性还受到如有机质、 $\mathrm{pH}$ 、盐度等环境因素以及种间竞 争等生物因素的影响. 沉积物有机质类型会直接影响产甲烷古菌的代谢方式, 而有效有机质含量的增加会 明显促进乙酸型产甲烷古菌的生长 ${ }^{[4,17]}$. 相比淡水湖泊, 高盐度和高碱度的湖泊中氢营养型产甲烷古菌和 SAMO 型甲烷氧化菌的数量会有显著增加 ${ }^{[20]}$. 碳源充足的情况下, 可以同时利用 $\mathrm{CO}_{2}$ 和乙酸的甲烷微菌目 和甲烷八叠球菌目可以迅速成为湖泊产甲烷微生物的优势种, 微生物种间竞争的压力也会增加 ${ }^{[27]}$. 在湖泊 中随着亚硝酸盐与硝酸盐的比例增加, 亚硝酸还原型厌氧甲烷氧化菌会逐渐挤占硝酸盐还原型的生存空 间 ${ }^{[41,70]}$. 产甲烷与甲烷氧化微生物在湖泊中的分布通常是多重因素决定的, 只有在特定条件下某一因子可 能成为影响其分布的主导因素.

\section{4 产甲烷与甲烷氧化微生物的研究方法进展}

关于产甲烷与甲烷氧化菌微生物的研究方法已在多篇综述中涉及 ${ }^{[91-93]}$, 本文着重介绍最近几年在湖泊 研究中涉及到的技术手段. (i) 微生物的培养技术极大推动了甲烷代谢微生物的研究, 湖泊生态系统也不例 外. 在 1950s, 厌氧纯培养技术得到了长足发展, 使得产甲烷古菌的分类也取得了较大的进展. 近年来随着厌 氧甲烷氧化古菌的发现, 多基质混合培养基的方法可以帮助研究人员获得仅有少量核心厌氧甲烷氧化微生 物组成的富集物, 有助于进一步开展单个微生物的富集分离和功能研究 ${ }^{[94]}$. (ii) 在针对产甲烷菌和甲烷氧 化菌的研究中, 功能基因检测发挥了重要的作用. 基于 $m c r A$ 和 $p m o A$ 的产甲烷菌与甲烷氧化菌的特定探针, 能够便捷地检测自然湖泊生态系统中是否存在相关微生物. 分子探针的研究方法在深水湖泊或者塞营养型 湖泊中得到了广泛的运用 ${ }^{[95-96]}$, 如通过分子探针结合显微观察的方法发现甲烷氧化古菌与硫酸盐还原菌形 成的外壳型共生体, 成功地从生物学角度证明了两种微生物存在共生关系 ${ }^{[97]}$. 事实上, 微生物中的基因信 息极为丰富, 现有信息只占全部基因信息的 $1 \%$. 因此如果能够测定完整基因序列, 对微生物的生命活动会 有更为详细的了解. (iii) 随着高通量测序技术的发展, 微生物基因组和宏基因组技术在湖泊研究中也有较 多应用 ${ }^{[98]}$. 针对基因表达过程所涉及的转录与蛋白质翻译过程的宏转录组和宏蛋白组也是重要的研究手 段. 研究人员将宏转录技术应用于甲烷氧化菌的应用当中, 可以有效甄别出水体中存在的产甲烷是否来自 于产甲烷功能基因的表达 ${ }^{[11]}$. (iv) 单细胞技术在甲烷微生物研究领域获得长足发展, 它以单细胞为研究对 象, 能够不依赖分离纯培养而获得所有遗传信息 ${ }^{[24]}$. 实际上, NC10 门细菌的发现与深人研究就是依赖单细 胞与组学技术的完美结合 ${ }^{[73,99]}$. 近几年, 新发现的厌氧甲烷氧化与好氧水体产甲烷过程已经成为湖泊生态 系统最活跃的研究方向. 由于此类功能微生物纯培养的难度较高, 往往需要灵活运用上述多种研究手段. 不 过可以预期, 湖泊生态系统中有关甲烷产生和消耗过程的研究将在分子生物学技术的推动下, 揭示更多未 知的微生物类群和代谢过程.

\section{5 展望}

1) 甲烷在湖泊生态系统中的迁移转化过程已经得到了广泛的研究, 这些过程中涉及的产甲烷微生物与 甲烷氧化微生物也逐渐被揭示; 然而有氧产甲烷微生物与厌氧甲烷氧化微生物等新物种的发现, 强烈指示 湖泊环境中仍有许多未知的微生物类群和反应途径值得我们去探索. 深水湖泊生态系统由于其天然的溶解 氧浓度梯度, 为开展甲烷转化相关研究提供了理想的实验场. 综合运用宏基因组、宏转录组、蛋白组学手段 以及分离培养、单细胞基因组等技术, 开展深水湖泊功能微生物及其代谢途径研究预期可能取得新发现. 此 外, 富营养化浅水湖泊频繁暴发的蓝藻水华, 强烈改变着湖泊局部区域的溶解氧条件, 此时产甲烷与甲烷氧 化过程呈现何种特征, 也亟待开展相关研究.

2) 不仅如此, 产甲烷与甲烷氧化过程还耦合硫循环、磷循环、氮循环和铁锰循环等过程,但是这些过程 与甲烷循环过程的耦合机制以及其中涉及的微生物生命代谢过程还不清楚, 如与 NC10 门极度相似微生物 既可以产甲烷, 也能完成亚硝酸盐还原; 又如在北极地区湖泊中硫酸盐还原细菌也可能完成甲烷氧化过程. 因此,揭示这些元素循环过程以及彼此之间的耦合效应,是未来湖泊物质循环研究的重要方向. 
3) 环境条件,如温度、溶解氧、有机质输人量等对产甲烷与甲烷氧化微生物的活性与丰度都存在重要的 影响, 而且在不同区域与季节, 这些因素的调控方式与结果也会存在差异, 从而最终影响湖泊甲烷释放量. 因此,针对湖泊生态系统的研究要格外重视环境变动对甲烷释放量的影响,尤其重视多因子的复合效应.

\section{6 参考文献}

[ 1 ] Kirschke S, Bousquet P, Ciais P et al. Three decades of global methane sources and sinks. Nature Geoscience, 2013,6 (10) : 813-823. DOI: 10.1038/ngeo1955.

[ 2 ] Roland FA, Darchambeau F, Morana C et al. Emission and oxidation of methane in a meromictic, eutrophic and temperate lake (Dendre, Belgium). Chemosphere, 2017, 168: 756-764. DOI: 10.1016/j.chemosphere.2016.10.138.

[ 3 ] Verpoorter C, Kutser T, Seekell DA et al. A global inventory of lakes based on high-resolution satellite imagery. Geophysical Research Letters, 2014, 41(18) : 6396-6402. DOI: 10.1002/2014gl060641.

[ 4 ] Townsend-Small A, Disbennett D, Fernandez JM et al. Quantifying emissions of methane derived from anaerobic organic matter respiration and natural gas extraction in Lake Erie. Limnology and Oceanography, 2016, 61 (S1): S356-S366. DOI: $10.1002 / \operatorname{lno} .10273$.

[ 5 ] Wik M, Varner RK, Anthony KW et al. Climate-sensitive northern lakes and ponds are critical components of methane release. Nature Geoscience, 2016, 9(2) : 99-105. DOI: 10.1038/ngeo2578.

[ 6 ] Crowe SA, Katsev S, Leslie K et al. The methane cycle in ferruginous Lake Matano. Geobiology, 2011, 9(1): 61-78. DOI: $10.1111 /$ j.1472-4669.2010.00257.x.

[ 7 ] Chen YG, Bai XH, Li XH et al. A primary study of the methane flux on the water-air surface of eight lakes, China. J lake $S c i, 2007,19(1): 11-17$. DOI : 10.18307/2007.0102. [陈永根, 白晓华, 李香华等. 中国 8 大湖泊冬季水-气界面甲 烷通量初步研究. 湖泊科学, 2007, 19(1): 11-17.]

[ 8 ] Samad MS, Bertilsson S. Seasonal variation in abundance and diversity of bacterial methanotrophs in five temperate lakes. Front Microbiol, 2017, 8(142) : 1-12. DOI: 10.3389/fmicb.2017.00142.

[ 9 ] Segers R. Methane production and methane consumption: A review of processes underlying wetlandmethane fluxe. Biogeochemistry, 1998, 41 : 23-51.

[10] Bogard MJ, Del Giorgio PA, Boutet L et al. Oxic water column methanogenesis as a major component of aquatic $\mathrm{CH}_{4}$ fluxes. Nature Communication, 2014, 5(7) : 5350. DOI: 10.1038/ncomms6350.

[11] Yao M, Henny C, Maresca JA. Freshwater bacteria release methane as a byproduct of phosphorus acquisition. Applied Environmental Microbiology, 2016, 82 (23) : 6994-7003. DOI: 10.1128/AEM.02399-16.

[12] Tang KW, Mcginnis DF, Ionescu D et al. Methane production in oxic lake waters potentially increases aquatic methane flux to air. Environmental Science \& Technology Letters, 2016, 3(6) : 227-233. DOI: 10.1021/acs.estlett.6b00150.

[13] Lecher AL, Chuang PC, Singleton M et al. Sources of methane to an Arctic lake in Alaska: An isotopic investigation. Journal of Geophysical Research-Biogeosciences, 2017, 122(4) : 753-766. DOI: 10.1002/2016jg003491.

[14] Miller SM, Miller CE, Commane R et al. A multi-year estimate of methane fluxes in Alaska from CARVE atmospheric observations. Global Biogeochem Cycles, 2016, 30(10) : 1441-1453. DOI: 10.1002/2016GB005419.

[15] Oswald K, Milucka J, Brand A et al. Light-dependent aerobic methane oxidation reduces methane emissions from seasonally stratified lakes. PLoS One, 2015, 10(7) : e0132574. DOI: 10.1371/journal.pone.0132574.

[16] Ricão Canelhas M, Denfeld BA, Weyhenmeyer GA et al. Methane oxidation at the water-ice interface of an ice-covered lake. Limnology and Oceanography, 2016, 61(S1) : S78-S90. DOI: 10.1002/lno.10288.

[17] Musenze RS, Fan L, Grinham A et al. Methane dynamics in subtropical freshwater reservoirs and the mediating microbial communities. Biogeochemistry, 2016, 128: 233-255. DOI: 10.1007/s10533-016-0206-8.

[18] Yang J, Jiang H, Dong H et al. Diversity of carbon monoxide-oxidizing bacteria in five lakes on the Qinghai-Tibet Plateau, China. Geomicrobiology Journal, 2013, 30(8) : 758-767. DOI: 10.1080/01490451.2013.769652.

[19] Roland FE, Darchambeau F, Morana C et al. Nitrous oxide and methane seasonal variability in the epilimnion of a large tropical meromictic lake (Lake Kivu, East-Africa). Aquatic Sciences, 2016, 79(2) : 209-218. DOI: 10.1007/s00027016-0491-2.

[20] Savvichev AS, Kokryatskaya NM, Zabelina SA et al. Microbial processes of the carbon and sulfur cycles in an ice-covered, 
iron-rich meromictic lake Svetloe (Arkhangelsk region, Russia). Environmental Microbiology, 2017, 19(2) : 659-672. DOI: $10.1111 / 1462-2920.13591$.

[21] He Z, Cai C, Wang J et al. A novel denitrifying methanotroph of the NC10 phylum and its microcolony. Science Report, 2016, 6: 32241. DOI: 10.1038/srep32241 (2016).

[22] Yang P, He JF, Zhang F et al. Progress of polar methanogenic communicity studies. Chinese Journal of Polar Research, 2016, 28 (1) : 145-151. DOI: 10.13679/j.jdyj.2016.1.145. [杨鹏, 何建锋, 张芳等. 极地产甲烷菌研究进展. 极地 研究, 2016, 28(1): 145-151.]

[23] Li YS, Li YM, Ouyang ZY. Progress of methanogenic microbes. Environmental Science, 2014, 35( 5) : 2025-2030. DOI: 10.13227/j.hjkx.2014.05.056. [李显珊, 李耀明, 欧阳志云. 产甲烷微生物研究概况. 环境科学, 2014, 35(5): 2025-2030.]

[24] Preheim SP, Olesen SW, Spencer SJ et al. Surveys, simulation and single-cell assays relate function and phylogeny in a lake ecosystem. Nature Microbiology, 2016, 1(9) : 16130. DOI: 10.1038/nmicrobiol.2016.130.

[25] Deng Y, Liu Y, Dumont M et al. Salinity affects the composition of the aerobic methanotroph community in alkaline lake sediments from the Tibetan Plateau. Microbial Ecology, 2017, 73(1) : 101-110. DOI: 10.1007/s00248-016-0879-5.

[26] Liu Y, Conrad R, Yao T et al. Change of methane production pathway with sediment depth in a lake on the Tibetan plateau. Palaeogeography, Palaeoclimatology, Palaeoecology, 2017, 474: 279-286. DOI: 10.1016/j.palaeo.2016.06.021.

[27] Borrel G, Jezequel D, Biderre-Petit C et al. Production and consumption of methane in freshwater lake ecosystems. Res Microbiol, 2011, 162(9) : 832-847. DOI: 10.1016/j.resmic.2011.06.004.

[28] Tang KW, Mcginnis DF, Frindte K et al. Paradox reconsidered: Methane oversaturation in well-oxygenated lake waters. Limnology and Oceanography, 2014, 59(1) : 275-284. DOI: 10.4319/lo.2014.59.1.0275.

[29] Murrell JC. The aerobic methane oxidizing bacteria (Methanotrophs). Handbook of Hydrocarbon and Lipid Microbiology, 2010: 1953-1966. DOI : 10.1007/978-3-540-77587-4_143.

[30] Horn C, Metzler P, Ullrich K et al. Methane storage and ebullition in monimolimnetic waters of polluted mine pit lake Vollert-Sued, Germany. Science of the Total Environment, 2017, s584/585: 1-10. DOI: 10.1016/j.scitotenv.2017.01.151.

[31] Liu L, Xu M, Li R et al. Timescale dependence of environmental controls on methane efflux from Poyang Hu, China. Biogeosciences, 2017, 14(8) : 2019-2032. DOI: 10.5194/bg-14-2019-2017.

[32] Bastviken D, Cole JJ, Pace ML et al. Fates of methane from different lake habitats: Connecting whole-lake budgets and $\mathrm{CH}_{4}$ emissions. Journal of Geophysical Research: Biogeosciences, 2008, 113( G2) : 61-74. DOI: 10.1029/2007jg000608.

[33] Shen LD, Hu BL, Zhang P. Progress in study on microorganisms for reponsible for anaerobic oxidation of methane. Acta Pedologica Sinica, 2011, 48(3) : 619-628. [沈李东, 胡宝兰, 张平. 甲烷厌氧氧化微生物的研究进展. 土壤学报, $2011,48(3)$ : 619-628.

[34] Valentine, David R, William S. New perspective on anaerobic methane oxidation. Environmental Microbiology, 2000, 2 ( 5 ) : 477-484. DOI: 10.1046/j.1462-2920.2000.00135.x.

[35] Timmers PH, Suarez-Zuluaga DA, Van Rossem M et al. Anaerobic oxidation of methane associated with sulfate reduction in a natural freshwater gas source. ISME J, 2016, 10(6) : 1400-1412. DOI: 10.1038/ismej.2015.213.

[36] Knittel K, Boetius A. Anaerobic oxidation of methane: progress with an unknown process. Annual Review Microbiology, 2009, 63: 311-334. DOI: 10.1146/annurev.micro.61.080706.093130.

[37] Hu S, Zeng RJ, Burow LC et al. Enrichment of denitrifying anaerobiec methane oxidizing microorganisms. Environmental Microbiology Report, 2009, 1(5) : 377-384. DOI: 10.1111/j.1758-2229.2009.00083.x.

[38] Strous M, Jetten MSM. Anaerobic oxidation of methane and ammonium. Annual Review Microbiology, 2004, 58(1) : 99 117. DOI: 10.1146 /annurev.micro.58.030603.123605.

[39] Zigah PK, Oswald K, Brand A et al. Methane oxidation pathways and associated methanotrophic communities in the water column of a tropical lake. Limnology and Oceanography, 2015, 60(2) : 553-572. DOI: 10.1002/lno.10035.

[40 ] Welte CU, Rasigraf O, Vaksmaa A et al. Nitrate- and nitrite-dependent anaerobic oxidation of methane. Environmental Microbiology Repeport, 2016, 8(6) : 941-955. DOI: 10.1111/1758-2229.12487.

[41] Niemann H, Losekann T, De Beer D et al. Novel microbial communities of the Haakon Mosby mud volcano and their role as a methane sink. Nature, 2006, 443(7113): 854-858. DOI: 10.1038/nature05227.

[42] Zhang JC, Xu YQ, Lu YH. Microbial mechanisms of methane production and oxidation in terrestrial ecosystems. Acta Eco- 
logica Sinica, 2015, 35(20) : 6592-6603. DOI: 10.5846 /stxb201507091459. [张坚超, 徐臆钦, 陆雅海. 陆地生态 系统甲烷产生和氧化过程的微生物机理. 生态学报, 2015, 35(20): 6592-6603.]

[43] Oswald K, Milucka J, Brand A et al. Aerobic gammaproteobacterial methanotrophs mitigate methane emissions from oxic and anoxic lake waters. Limnology and Oceanography, 2016, 61(S1): S101-S118. DOI: 10.1002/lno.10312.

[44] Grossart HP, Frindte K, Dziallas C et al. Microbial methane production in oxygenated water column of an oligotrophic lake. PNAS, 2011, 108(49) : 19657-19661. DOI: 10.1073/pnas.1110716108.

[45] Wang Q, Dore JE, Mcdermott TR. Methylphosphonate metabolism by Pseudomonas sp. populations contributes to the methane oversaturation paradox in an oxic freshwater lake. Environmental Microbiology, 2017, 19(6) : 2366-2378. DOI: 10. $1111 / 1462-2920.13747$.

[46] Groskopf R, Stubner S, Liesack W. Novel euryarchaeotal lineages detected on rice roots and in the anoxic bulk soil of flooded rice microcosms. Applied and Environmental Microbiology, 1998, 64(12) : 4983-4989.

[47] Paul K, Nonoh JO, Mikulski L et al. "Methanoplasmatales," thermoplasmatales-related archaea in termite guts and other environments, are the seventh order of methanogens. Applied and Environmental Microbiology, 2012, 78(23) : 8245-8253. DOI: 10.1128/AEM.02193-12.

[48] Liu Y, Whitman WB. Metabolic, phylogenetic, and ecological diversity of the methanogenic archaea. ANNALS, 2008, 1125 (1) : 171-189. DOI: 10.1196/annals.1419.019.

[49] Jeanlouis G, Bharat KCP, Bernard O et al. Taxonomic, phylogenetic, and ecological diversity of methanogenic archraea. Anaerobe, 2000, 6(4) : 205-226. DOI: 10.1006/anae.2000.0345.

[50] Simankova MV, Parshina SN, Tourova TP et al. Methanosarcina lacustris sp. nov, a new psychrotolerant methanogenic archaeon from anoxic lake sediments. System Applied Microbiology, 2001, 24 ( 3 ) : 362-367. DOI: 10. 1078/07232020-00058.

[51] Scholten JCM, Stams AJM. Isolation and characterization of acetate-utilizing anaerobes from a freshwater sediment. Microbial Ecology, 2000, 40(4) : 292-299.

[52] Whitby C, Earl J, Lanyon C et al. The molecular diversity of the methanogenic community in a hypereutrophic freshwater lake determined by PCR-RFLP. Journal of Applied Microbiology, 2004, 97(5) : 973-984.

[53] Yang J, Roey A, Melaine K et al. Structure and function of methanogenic microbial communities in sediments of Amazonian lakes with different water types. Environmental Microbiology, 2016, 18(12) : 5082-5100. DOI: 10.1111/1462-2920.13491.

[54] Wang BY, Liu JM, Han ZY et al. Recent progress and classification of methanogens. Genomics and Applied Biology, 2014, 33(2) : 418-425. DOI: 10.13417/j.gab.033.000418. [王保玉, 刘建民, 韩作颖等. 产甲烷菌的分类及研究进 展. 基因组学与应用生物学, $2014,33(2)$ : 418-425.]

[55] Franzmann PD, Springer N, Ludwig W et al. A methanogenic archaeon from Ace Lake, Antarctica: Methanococcoides burtonii sp. nov. System Applied Microbiology, 1992, 15(4) : 573-581.

[56] Stoeva MK, Arisbrosou S, Chetelat J et al. Microbial community structure in lake and wetland sediments from a high Arctic polar desert revealed by targeted transcriptomics. PLoS One, 2014, 79(2) : 348-358. DOI: 10.1111/j.1574-6941.2011. 01221.x.

[57] Miskin I, Rhodes G, Lawlor K et al. Bacteria in post-glacial freshwater sediments. Microbiology, 1998, 144 (9): 2427-2439.

[58] Kotelnikova S, Macario AJ, Pedersen K. Methanobacterium subterraneum sp. nov., a new alkaliphilic, eurythermic and halotolerant methanogen isolated from deep granitic groundwater. International Journal of Systematic and Evolutionary Microbiology, 1998, 48(2) : 357-367. DOI: 10.1099/00207713-48-2-357.

[59] Lomans BP, Maas R, Luderer R et al. Isolation and characterization of Methanomethylovorans hollandica gen. nov., sp. nov., isolated from freshwater sediment, a methylotrophic methanogen able to grow on dimethyl sulfide and methanethiol. Applied and Environmental Microbiology, 1999, 65(8) : 3641-3650.

[60] Jones BE, Grant WD, Duckworth AW et al. Microbial diversity of soda lakes. Extremophiles, 1998, 2(3) : 191-200.

[61] Kirschbaum MUF, Bruhn D, Etheridge DM et al. A comment on the quantitative significance of aerobic methane release by plants. Functional Plant Biology, 2006, 33(6) : 521-530. DOI: 10.1071/FP06051.

[62] Angel R, Matthies D, Conrad R. Activation of methanogenesis in arid biological soil crusts despite the presence of oxygen. PLoS One, 2011, 6(5) : e20453. DOI: 10.1371/journal.pone.0020453. 
[63] Del VDA, Karl DM. Aerobic production of methane from dissolved water-column methylphosphonate and sinking particles in the North Pacific Subtropical Gyre. Aquatic Microbial Ecology, 2014, 73(2) : 93-105. DOI: 10.3354/ame01714.

[64] Damm E, Rudels B, Schauer U et al. Methane excess in arctic surface water- triggered by sea ice formation and melting. Science Report, 2015, 5: 161-179.

[65] Yun JL, Wang YF, Zhang HX et al. Ecology of aerobic methane oxidizing bacteria (methanotrophs). Acta Ecologica Sini$c a, 2013,33$ (21) : 6774-6785. DOI : 10.5846 /stxb201207171013. [贠娟莉, 王艳芬, 张洪勋. 好氧甲烷氧化菌生态 学研究进展. 生态学报, 2013, 33(21): 6774-6785.]

[66] Costello AM, Auman AJ, Macalady JL et al. Estimation of methanotroph abundance in a freshwater lake sediment. Environmental Microbiology, 2002, 4(8) : 443-450. DOI: 10.1046/j.1462-2920.2002.00318.x.

[67] Deutzmann JS, Schink B. Anaerobic oxidation of methane in sediments of Lake Constance, an oligotrophic freshwater lake. Applied Environmental Microbiology, 2011, 77(13) : 4429-4436. DOI: 10.1128/AEM.00340-11.

[68] Rahalkar M, Schink B. Comparison of aerobic methanotrophic communities in littoral and profundal sediments of Lake Constance by a molecular approach. Applied Environmental Microbiology, 2007, 73(13) : 4389-4394. DOI: 10.1128/AEM. 02602-06.

[69] Silke S, Ralf C. Effect of algal deposition on acetate and methane concentrations in the profundal sediment of a deep lake (Lake Constance). FEMS Microbiol Ecol, 1995, 16(4) : 251-259. DOI: 10.1111/j.1574-6941.1995.tb00289.x.

[70] Dumont M, Pommerenke B, Casper P et al. DNA-, rRNA- and mRNA-based stable isotope probing of aerobic methanotrophs in lake sediment. Environmental Microbiology, 2011, 13(5) : 1153-1167. DOI: 10.1111/j.1462-2920.2010.02415.x.

[71] Liu Y, Zhang J, Zhao L et al. Aerobic and nitrite-dependent methane-oxidizing microorganisms in sediments of freshwater lakes on the Yunnan Plateau. Applied Microbiology Biotechnology, 2015, 99(5) : 2371-2381. DOI: 10. 1007/s00253014-61415.

[72] Antony CP, Kumaresan D, Hunger S et al. Microbiology of Lonar Lake and other soda lakes. ISME J, 2013, 7(3) : 468476. DOI: $10.1038 /$ ismej.2012.137.

[73] Horikoshi K, Takai K. Rapid detection and quantification of members of the archaeal community by quantitative PCR using fluorogenic probes. Applied Environmental Microbiology, 2000, 66(11) : 5066-5072. DOI: 10.1128/AEM.66.11.50665072.2000 .

[74] Raghoebarsing AA, Pol A, Van De Pas-Schoonen KT et al. A microbial consortium couples anaerobic methane oxidation to denitrification. Nature, 2006, 440(7086) : 918-921. DOI: 10.1038/nature04617.

[75] Chen J, Dick R, Lin JG et al. Current advances in molecular methods for detection of nitrite-dependent anaerobic methane oxidizing bacteria in natural environments. Applied Microbiology Biotechnology, 2016, 100(23) : 9845-9860. DOI: 10. 1007/s00253-016-7853-5.

[76] Deutzmann JS, Worner S, Schink B. Activity and diversity of methanotrophic bacteria at methane seeps in eastern Lake Constance sediments. Applied Environmental Microbiology, 2011, 77(8) : 2573-2581. DOI: 10.1128/AEM.02776-10.

[77] Weber HS, Habicht KS, Thamdrup B. Anaerobic methanotrophic archaea of the ANME-2d cluster are active in a low-sulfate, iron-rich freshwater sediment. Front Microbiol, 2017, 8: 619. DOI: 10.3389/fmicb.2017.00619.

[78] Liu Y, Whitman WB. Metabolic, phylogenetic, and ecological diversity of the methanogenic archaea. Annals of the New York Academy of Sciences, 2008, 1125(1) : 171-189. DOI: 10.1196/annals.1419.019.

[79] Ragsdale SW, Kumar M. Nickel-containing carbon monoxide dehydrogenase/acetyl-CoA synthase. Chemical Reviews, 1996, 96(7): 2515-2540.

[80] Tsutsumi M, Kojima H, Fukui M. Vertical profiles of abundance and potential activity of methane-oxidizing bacteria in sediment of Lake Biwa, Japan. Microbes and Environments, 2012, 27(1) : 67-71. DOI: 10.1264/jsme2.ME11285.

[81] Popp TJ, Chanton JP, Whiting GJ et al. Evaluation of methane oxidation in the rhizosphere of a Carex dominated fen in north central Alberta, Canada. Biogeochemistry, 2000, 51(3) : 259-281. DOI: 10.1023/A: 1006452609284.

[82] Xing P, Hu WT, Wu YF et al. Major progress in microbial ecology of hypoxia in the shallow eutrophic lakes. J Lake Sci, 2015, 27(4) : 567-574. DOI: 10.18307/2017.0402. [邢鹏, 胡万婷, 吴瑜凡等. 浅水湖泊湖泛黑水团中的微生物生 态学研究进展. 湖泊科学, 2017, 27(4): 567-574.]

[83] Fuchs A, Lyautey E, Montuelle B et al. Effects of increasing temperatures on methane concentrations and methanogenesis during experimental incubation of sediments from oligotrophic and mesotrophic lakes. Journal of Geophysical Research: Bio- 
geosciences, 2016, 121(5) : 1394-1406. DOI: 10.1002/2016jg003328.

[84] Palma-Silva C, Marinho CC, Albertoni EF et al. Methane emissions in two small shallow neotropical lakes: The role of temperature and trophic level. Atmospheric Environment, 2013, 81: 373-379. DOI: 10.1016/j.atmosenv.2013.09.029.

[85] Li M, Guo J, Shi Z et al. Bacterial community structure in lakes on the northeastern Qinghai-Tibetan Plateau. Chinese Journal of Appplied Environmental Biology, 2013, 19(5) : 750-758. DOI: 10.3724/sp.j.1145.2013.00750.

[86] Stibal M, Gozdereliler E, Cameron KA et al. Microbial abundance in surface ice on the Greenland Ice Sheet. Front Microbiol, 2015, 6: 225. DOI: 10.3389/fmicb.2015.00225.

[87] Sundh I, Bastviken D, Tranvik LJ. Abundance, activity, and community structure of pelagic methane-oxidizing bacteria in temperate lakes. Applied and Environmental Microbiology, 2005, 71(11) : 6746-6752.

[88 ] Kraemer BM, Chandra S, Dell AI et al. Global patterns in lake ecosystem responses to warming based on the temperature dependence of metabolism. Global Change Biology, 2017, 23(5) : 1881-1890. DOI: 10.1111/gcb.13459.

[89] Burrows MT, Schoeman DS, Richardson AJ et al. Geographical limits to species-range shifts are suggested by climate velocity. Nature, 2014, 507(7493) : 492-495. DOI: 10.1038/nature12976.

[90] Franzmann PD, Liu Y, Balkwill DL et al. Methanogenium frigidum sp. nov., a psychrophilic, H2-Using methanogen from Ace Lake, Antarctica. International Journal of Systematic and Evolutionary Microbiology, 1997, 47(4) : 1068-1072.

[91] Fan QX, Wu J, Chang JL et al. Research progress in denitrifying anaerobic methane oxidation. Chinese Journal Ecology, 2015, 34(6) : 1747-1754. DOI : 10.13292/j.1000-4890.2015.0163. [范秋香, 吴菁, 常佳丽等. 反硝化型甲烷厌氧氧 化的研究进展. 生态学杂志, 2015, 34(6): 1747-1754.]

[92] Deng YC, Che XR, Wu YB et al. A review of the physiological and ecological characteristics of methanotrophs and methanotrophic community diversity in the natural wetlands. Acta Ecologica Sinica, 2015, 35(14) : 4579-4591. DOI: 10.5846/ stxb201305060936. [邓永翠, 车晓荣, 吴伊波等. 好氧甲烷氧化菌生理生态特征及其在自然湿地中的群落多样性 研究进展. 生态学报, 2015, 35(14) : 4579-4591.]

[93] Zhu JP, Sun L. Research progress of anaerobic oxidation of methane. China Biogas, 2010, 28(2):30-37. [朱静平, 孙 丽. 甲烷厌氧氧化技术研究进展. 中国沼气, 2010, 28(2): 30-37.]

[94] Ettwig KF, Van Alen T, Van De Pas-Schoonen KT et al. Enrichment and molecular detection of denitrifying methanotrophic bacteria of the NC10 phylum. Applied Environmental Microbiology, 2009, 75(11) : 3656-3662. DOI: 10.1128/AEM. 00067-09.

[95] Vaksmaa A, Jetten MS, Ettwig KF et al. McrA primers for the detection and quantification of the anaerobic archaeal methanotroph 'Candidatus Methanoperedens nitroreducens'. Applied Microbiology Biotechnology, 2017, 101(4) : 1631-1641. DOI: $10.1007 / \mathrm{s} 00253-016-8065-8$.

[96] Luesken FA, Zhu B, Van Alen TA et al. PmoA primers for detection of anaerobic methanotrophs. Applied Environmental Microbiology, 2011, 77(11) : 3877-3880. DOI: 10.1128/AEM.02960-10.

[97] Wu ML, Ettwig KF, Jetten MSM et al. A new intra-aerobic metabolism in the nitrite-dependent anaerobic methane-oxidizing bacterium Candidatus 'Methylomirabilis oxyfera'. Biochemical Society Transactions, 2011, 39(1) : 243-248. DOI: 10.1042/BST0390243.

[98] Fischer MA, Gullert S, Neulinger SC et al. Evaluation of 16S rRNA gene primer pairs for monitoring microbial community structures showed high reproducibility within and low comparability between datasets generated with multiple archaeal and bacterial primer pairs. Front Microbiol, 2016, 7: 1297. DOI: 10.3389/fmicb.2016.01297.

[99] Haroon MF, Hu S, Shi Y et al. Anaerobic oxidation of methane coupled to nitrate reduction in a novel archaeal lineage. Nature, 2013, 500(7464) : 567-570. DOI: 10.1038/nature12375. 